Artículo

\title{
Epidemia, economía atlántica y aprendizaje social. La fiebre amarilla en España*
}

\author{
Víctor A. Luque de Haro** (ID \\ Universidad de Almería

\section{Andrés Sánchez Picón ID} \\ Universidad de Almería

\section{José Joaquín García Gómez $\mathbb{D}$} \\ Universidad de Almería
}

\section{INFORMACIÓN DEL ARTÍCULO}

Historia del artículo:

Recibido: 7 de junio de 2020

Aceptado: 29 de noviembre de 2020

On-line: 12 de abril de 2021

\section{Códigos JEL}

N33

I14

I18

J18

Palabras clave

Epidemias

Fiebre amarilla

Aprendizaje social

Desigualdad

\section{JEL classification:}

N33

I14

I18

J18

Keywords:

Epidemics

Yellow fever

Social learning

Inequality

\begin{abstract}
R E S U M E N
El presente trabajo analiza las epidemias de fiebre amarilla que azotaron el sur de España durante el siglo xvIII y las primeras décadas del siglo xix. Destaca la vinculación de la fiebre amarilla con el desarrollo del sistema comercial atlántico de la época, así como su influencia en las reformas sanitarias e higiénicas de los años siguientes. Los resultados muestran cómo las recomendaciones de los expertos, unidas a la experiencia de brotes anteriores, incentivaron estrategias para reducir la exposición al patógeno, entre las que destacó la huida de las poblaciones infectadas. La desigualdad en la capacidad para evitar el contagio tuvo como consecuencia una mayor letalidad de la enfermedad entre las clases socioeconómicas menos privilegiadas.
\end{abstract}

(C) 2020 Asociación Española de Historia Económica

\section{Epidemic, Atlantic economy and social learning. Yellow fever in Spain}

\section{A B S T R A C T}

This work analyzes the yellow fever outbreaks that affected southern Spain during the 18th century and the first decades of the 19th century. The link between yellow fever and the development of the Atlantic commercial system, as well as its influence on the sanitary and hygienic reforms of the following years. The results show how the recommendations of the experts, together with the experience of previous outbreaks encouraged strategies to reduce exposure to the pathogen, among which the flight of infected populations stood out. The differences in the ability to avoid contagion resulted in a higher lethality of the disease among the less privileged socioeconomic classes.

(C) 2020 Asociación Española de Historia Económica

\footnotetext{
* Este trabajo ha sido financiado por el Ministerio de Ciencia, Innovación y Universidades, a través del proyecto PGC2018-097817-B-C32.

** Autor para correspondencia.

Correo electrónico: Vld417@ual.es (Víctor Luque de Haro)
} 


\section{Introducción: fiebre amarilla y economía atlántica}

Las epidemias eran uno de los problemas que afrontaban recurrentemente las sociedades preindustriales (Pérez Moreda, 1980, p. 57; Livi Bacci, 1990). La literatura sobre la interrelación histórica entre las pandemias y el desarrollo económico es amplia, aunque desigual (Shaw-Taylor, 2020), siendo la peste negra del siglo xiv y la gripe de 1918 los episodios más estudiados (Rawcliffe y Clark, 2013; Phillips, 2014; Benedictow, 2018; Echeverri Dávila, 2018; Snowden, 2019). En cualquier caso, existe gran consenso en la diversidad de factores que influyen en las consecuencias demográficas y económicas de las epidemias (Alfani y Murphy, 2017; Alfani, 2020). Entre las menos estudiadas en el caso español se encuentra la fiebre amarilla de los siglos XVIII y XIX.

A comienzos del siglo XIX, esta epidemia era una de las principales amenazas a las que se enfrentaba la sanidad española, teniendo gran incidencia en las costas andaluzas durante la primera década del siglo y en todo el Mediterráneo español a lo largo de las dos siguientes (Pérez Moreda, 1980, p. 77; Rodríguez Ocaña y Martínez Navarro, 2008).

Los estragos de los brotes de fiebre amarilla, especialmente cuando afectan a poblaciones sin ningún grado de inmunidad, son comparables a los sufridos durante las epidemias de peste, tan características de los siglos anteriores (Pérez Moreda, 1980, p. 390; Peset, 2011, p. 585). Sin embargo, la fiebre amarilla no tuvo el alcance territorial de estas últimas ya que su escenario principal fueron los núcleos urbanos. Por esta razón, el impacto en términos demográficos no fue tan importante, aún teniendo consecuencias devastadoras en determinadas localidades (Nadal, 1966, pp. 102-104). Además, este fue un periodo de intensos trastornos demográficos a nivel nacional (tercianas y paludismo en el interior, y malas cosechas, especialmente hacia 1804) (Pérez Moreda, 2010, p. 306). Estas circunstancias explican que los ciclos epidémicos de fiebre amarilla hayan sido menos estudiados por la demografía histórica y la historia económica que otras epidemias -como la peste, el cólera, o la gripe de 1918- con una incidencia más generalizada (Pérez Moreda, 1980; Serrallonga i Urquidi, 1996; González García, 2013; Voigtländer y Voth, 2013; Chowell et al., 2014; Cilek, Chowell y Fariñas, 2018; Eiros Bouza, Bachiller Luque y Pérez Rubio, 2018). La menor presencia en la historiografía y la fuerte repercusión que tuvo en las ciudades en las que impactó, además de la atención actual por temas relacionados con las pandemias, justifican el interés del artículo que se presenta a continuación.

Este trabajo analiza el ciclo epidémico de fiebre amarilla que padecieron los litorales levantino y meridional de la península, así como Baleares y Canarias, durante el siglo xviII y comienzos del xIx y trata de responder a tres grandes cuestiones: las causas y procesos de extensión de la plaga, entre los que destaca el comercio atlántico; los efectos demográficos que produjo; y las estrategias de lucha contra la enfermedad por parte del sector público y de los individuos, prestando especial atención al fenómeno de la huida. A partir de datos cuantitativos y cualitativos, el artículo arroja luz acerca de las diferencias en el grado de supervivencia de la enfermedad según la capacidad de cada familia para evitar la exposición a la misma, algo que solía guardar relación con su estatus socioeconómico.

La relación entre las epidemias y el desarrollo económico es compleja y en absoluto lineal. Para las fases iniciales de la globalización económica, el incremento de los intercambios comerciales, al ser una poderosa palanca para la riqueza de las naciones, también alteraba los riesgos de las poblaciones humanas, mostrándolas vulnerables ante patógenos hasta entonces desconocidos. Avanzado el siglo xix y sobre todo durante el $x x$, el aumento del conocimiento científico sobre los mecanismos y vectores de los contagios, así como la mejora en los tratamientos y en la prevención de estas plagas, redujeron su letalidad y convirtieron algunos de estos episodios epidémicos en pasado (Mooney, 2015).

El ciclo de fiebre amarilla en el litoral español es una manifestación de la unificación de las diferentes redes humanas iniciada a mediados del siglo xv y que se alargaría hasta el ecuador del xviII, cuando es sustituida por la nueva red mundial que se construirá durante el proceso de industrialización, ese «largo» siglo xix que llega hasta 1914 (McNeill y McNeill, 2004)1.

El sistema mundial constituido con los grandes descubrimientos fue también el propulsor de un intercambio biológico inédito en la historia (Crosby, 1988). Las enfermedades se movieron entre continentes modificando el mapa de riesgos epidémicos a ambas orillas del Atlántico. Si la peste negra en la Baja Edad Media fue el primer paso en la unificación microbiana del mundo, la expansión atlántica sería el paso definitivo en la globalización de los contagios (Le Roy Ladurie, 1973). Las epidemias de fiebre amarilla ${ }^{2}$ estuvieron vinculadas a la apertura comercial, en concreto a la configuración de un sistema comercial atlántico organizado desde el siglo xvı por la Carrera de Indias (Martínez Shaw y Oliva Melgar, 2005; Lobato Franco y Oliva Melgar, 2013). Esta era una red marítima por donde se movían dinero y mercancías, pero también agentes patógenos. El sistema de flotas y galeones construía una red comercial que conectaba, en una de sus ramas, a Sevilla y Cádiz, una vez se trasladara el monopolio del comercio colonial, con Veracruz en Nueva España, uno de los mercados centrales del sistema comercial atlántico español (Stein y Stein, 2005).

Entre las modalidades del comercio triangular dentro del sistema atlántico, la principal coordinaba las manufacturas europeas con la exportación de esclavos africanos hacia el Caribe. De vuelta, y en especial con la flota que regresaba desde Veracruz, llegaba a Cádiz plata, añil y cochinilla (Stein y Stein, 2005, p. 157). Este comercio, unido a las transformaciones ecológicas y demográficas ocasionadas por las plantaciones de cañas de azúcar en el Caribe ${ }^{3}$, favorecieron la expansión

\footnotetext{
${ }^{1}$ Utilizamos el concepto de redes en la visión de historia global que sostienen McNeill y McNeill (2004).

${ }^{2}$ La medicina actual considera la fiebre amarilla como una enfermedad infecciosa aguda y contagiosa, caracterizada clínicamente por fiebre, hemorragias, vómitos negros e ictericia. Como endemia duradera, se observa en zonas de las costas atlánticas y del interior del continente sudamericano, en las islas de la América tropical y en África. Sin embargo, puede ser transportada a otras regiones que no estén muy elevadas con relación al nivel del mar, y cuya temperatura se mantenga entre 17 y $30^{\circ} \mathrm{C}$, de forma que el vector de la enfermedad -el mosquito Aedes aegyptipueda desarrollar su actividad (Vainio y Cutts, 1998; Toledo Curbelo, 2000; Restrepo, 2004; Jentes et al., 2011; Kraemer et al., 2015). En la actualidad, se estima que afecta anualmente a más de 200000 personas en regiones tropicales de África, Centroamérica y Sudamérica, provocando alrededor de 30000 fallecimientos (Monath, 2001; Gardner y Ryman, 2010, p. 243; Bennett, Dolin y Blaser, 2020, pp. 165-166).

${ }^{3}$ Las últimas investigaciones sugieren que el origen de la enfermedad actual estuvo en África, donde el virus del género flavivirus, que tenía su reservorio en ciertas especies de primates, saltó a los humanos (Curtin, 1993; Barrett y Monath, 2003; Restrepo, 2004; Barrett y Higgs, 2007, p. 219; Bennett, Dolin y Blaser, 2020, p. 2014). Entre las consecuencias de la revolución azucarera en el Caribe se encuentra el desarrollo del hábitat
} 
de la cepa africana de fiebre amarilla en el continente americano $^{4}$ (Curtin, 1993, pp. 347-348; Barrett y Higgs, 2007, p. 210; McNeill, 2010, pp. 15-62).

La intensificación del comercio colonial hizo que ya en el siglo xvIII la enfermedad llegase a los puertos europeos (Gardner y Ryman, 2010, p. 237). En Canarias la enfermedad impactó por primera vez en 1701 (Betancor Gómez, 2000). Los primeros casos de fiebre amarilla en la península ibérica se concentraron en Cádiz. De hecho, con la excepción del contagio de 1723 en Lisboa (Vainio y Cutts, 1998, p. 64) y de 1741 en Málaga (González de Sámano, 1858, p. 31; Guijarro Oliveras, 1948, p. 21), el resto de los brotes que alcanzaron las costas peninsulares a lo largo del siglo xviII se localizaron en dicha ciudad. Sin embargo, pocas décadas después de la liberalización del comercio colonial en 1765 y 1778, diferentes zonas costeras del sur y del levante peninsular sufrieron también la enfermedad en distintas oleadas (Nadal, 1966, pp. 100-108; Delgado Ribas, 1986; Rodríguez Ocaña, 1987; Morillon, Mafart y Matton, 2002).

No obstante, el puerto de Cádiz siguió canalizando la mayor parte del tráfico con las colonias americanas: si entre $1750 \mathrm{y}$ 1777 concentraba el 85,6\% de las importaciones, hacia 1798 1818 seguía controlando más del 62,4\% (Cuenca-Esteban, 2008). En cuanto a las exportaciones, García-Baquero (1984, p. 126) sitúa el valor de lo exportado desde Cádiz entre 1785 y 1788 en un promedio anual de unos 351 millones de reales, mientras que Málaga se situaría en unos 20 millones de reales y Sevilla en 10 millones.

La liberalización incrementó extraordinariamente el tráfico comercial (Fisher, 1993) 5 . Además, el aumento de la proporción de mercancías españolas (del 38\% en 1778 a un $52 \%$ en 1782 1796) apunta al dinamismo que produjo en el litoral español, donde Málaga o Barcelona serían nodos fundamentales de una activa red comercial mediterránea (Ringrose, 1996, pp. 170172 ) en la que los intercambios fueron cada vez mayores, aunque interrumpidos por las guerras revolucionarias (García-Baquero, 1984). Las plazas insertas en este sistema (Cádiz, Málaga, Cartagena, Alicante y Barcelona) protagonizaron los episodios epidémicos que vamos a tratar a continuación.

\section{Las epidemias de comienzos del siglo XIX}

A partir de una intensa revisión bibliográfica hemos elaborado un cuadro en el que se presentan los brotes de fiebre amarilla en España durante los siglos xviII y xix (ver anexo virtual). Se ha compilado una información lo más exhaustiva posible sobre los brotes de epidemias de fiebre amarilla durante los siglos XVIII y xIX a partir tanto de la revisión de la producción historiográfica sobre el tema, con especial atención a la basada en la recogida de datos sobre la incidencia de los

que permitió la supervivencia y reproducción del Aedes aegypti, además de la creación de las circunstancias económicas, demográficas y militares que favorecieron su circulación (McNeill, 2010, pp. 23-37).

${ }^{4}$ Aunque la literatura alude a episodios de fiebre amarilla anteriores, la mayoría de los autores señalan que las primeras epidemias de esta enfermedad en el Nuevo Mundo se produjeron a mediados del siglo xviı en Cuba, Barbados y México (Vainio y Cutts, 1998, p. 16; Tomori, 2002, p. 195; Gragg, 2003; Barrett y Higgs, 2007, pp. 210, 219; McNeill, 2010).

${ }^{5}$ Una visión escéptica sobre el impacto del libre comercio en Delgado (1986) y en García-Baquero (1984). El tema ha sido tratado también por otros autores (Fisher, 1981, 1993; Martínez Shaw, 1987; Bustos Rodríguez, 2008; Cuenca-Esteban, 2008; Martínez, 2010). mismos (Nadal, 1966; Iglesias Rodríguez, 1987; Hamer-Flores, 2018; Luque de Haro, 2020), como de la explotación de fuentes primarias como las memorias publicadas en la época (Aréjula, 1806; Mellado, 1811; De María, 1820; Bahí, 1822).

La mayoría de los autores de estas memorias eran médicos prestigiosos y ocuparon cargos de responsabilidad durante los brotes estudiados: Aréjula estuvo destinado en Cádiz durante la epidemia de 1800 y en Málaga durante la de 1804; Mellado era doctor en Medicina y su obra fue encargada por la Junta Superior de Sanidad de Cádiz en 1810; De María en 1800 integró la comisión médica nombrada por el Gobierno y estuvo destinado en Vélez Málaga en 1804; Bahí fue vocal de la Junta Superior de Sanidad de Cataluña durante la epidemia de Barcelona de 1821; Charles Maclean (1817) trabajaba para la East India Company; Fellowes (1815) como supervisor del departamento médico militar inglés de una división estacionada en el sur de España; Sykes (1838), vicepresidente de la Statistical Society of London, y Augustin (1909) redactó History of yellow fever durante su experiencia en el hospital de la marina estadounidense en el brote de fiebre amarilla de 1897 en Nueva Orleans. La extensión de la información recogida obliga, por motivos de espacio, a incluirla en un anexo virtual a disposición de los lectores.

Si durante el siglo xvIII los episodios de fiebre amarilla se habían concentrado en la ciudad de Cádiz, durante las décadas iniciales del xix se produce una notable dispersión geográfica de la incidencia, además de un aumento de su frecuencia. Así, durante el primer cuarto del siglo xIx podemos identificar cuatro oleadas según el número de poblaciones afectadas -1800 , 1804, 1811-1812 y 1821-. En 1800 se produjo la primera, con alcance en más de un núcleo de importancia, y que fue la más letal al superar los 60000 fallecimientos (ver figura 1). Durante este año los brotes se concentraron en la Andalucía occidental, destacando los casos de Cádiz, Sevilla y Jerez (C, S y J, respectivamente, en la figura 1). Al año siguiente, la enfermedad afectó a Medina Sidonia, y en 1803 a Málaga y Barcelona.

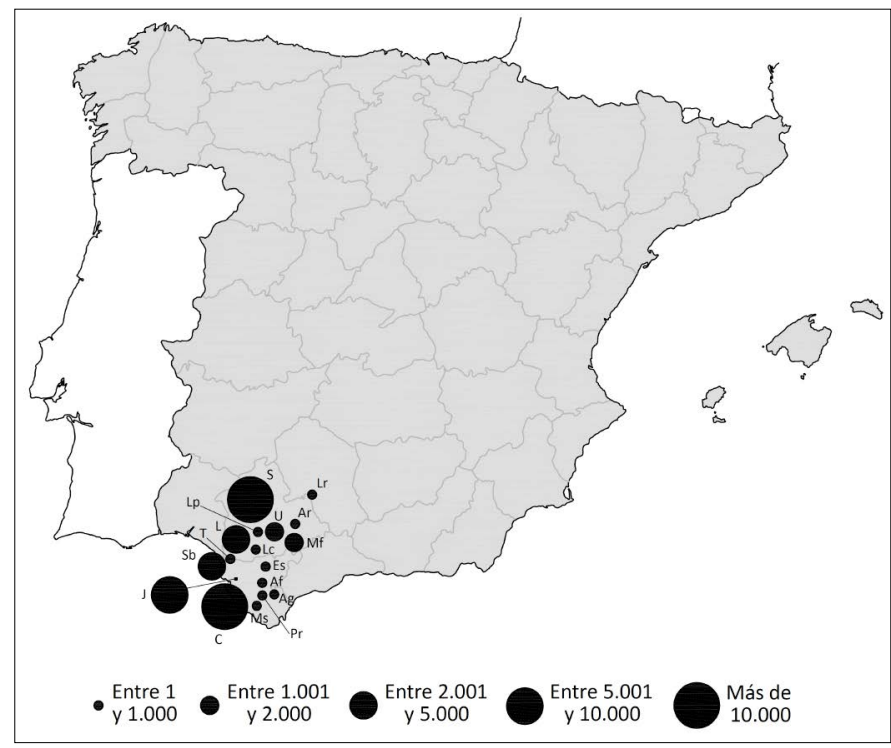

Nota: El brote de Cádiz incluye los fallecimientos registrados en Cádiz, San Fernando, Puerto de Santa María, Puerto Real, Chiclana y Rota. El de Sevilla, los de Coria y Dos Hermanas.

Figura 1. Localidades afectadas por la fiebre amarilla durante la oleada de 1800 y magnitud de los brotes (número de fallecidos).

Fuente: elaboración propia. Ver anexo virtual. 
En 1804 se produjo la segunda oleada epidémica (ver figura 2). Durante este año la fiebre amarilla afectó al menos a 25 poblaciones del Sur y el Sureste peninsular, provocando más de 48150 defunciones. Destacan por el mayor número de fallecidos los episodios de Málaga y Cartagena -11464 y 11445 respectivamente- ( $\mathrm{M}$ y Ct en la figura 2). Entre 1810 y 1812 la oleada se concentró en el sureste peninsular (ver figura 3). Con la excepción de los brotes de Cádiz en 1810 y 1813, el resto de los episodios durante este periodo afectaron a municipios de las prefecturas napoleónicas de Granada, Murcia y Alicante. Durante estos años, además de la ciudad portuaria de Cartagena, se vieron afectadas otras del interior, como Murcia, Lorca, Jumilla, Elche, Cieza y Turre o ciudades del litoral sin contacto directo con las Américas como Cuevas o Vera (Ct, Mu, Lo, J, El, $\mathrm{Ci}, \mathrm{Tu}, \mathrm{Cu}$ y V, respectivamente, en la figura 3).

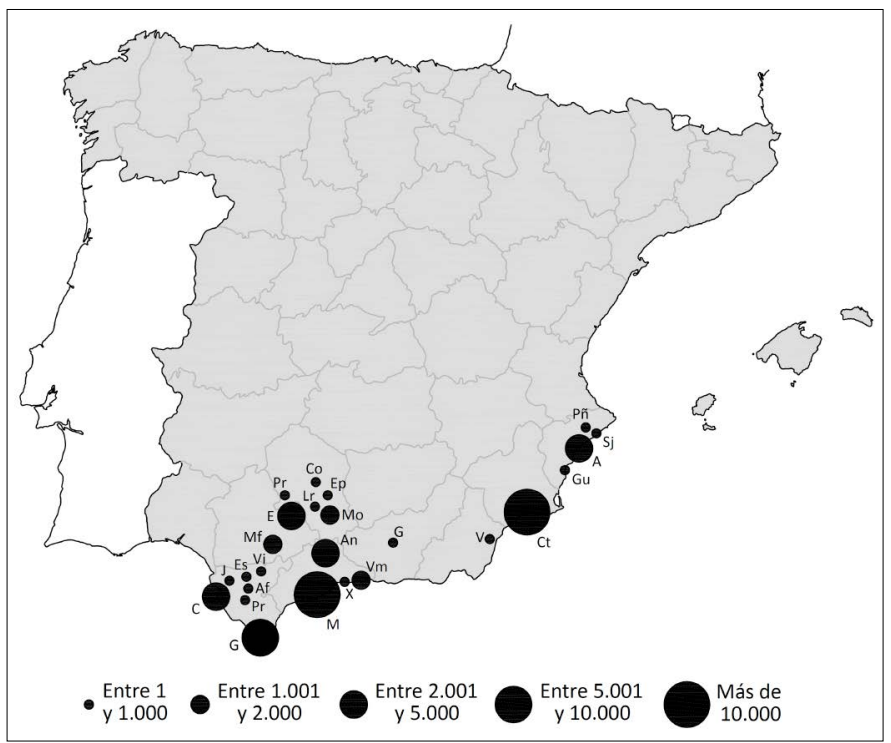

Figura 2. Localidades afectadas por la fiebre amarilla durante la oleada de 1804 y magnitud de los brotes (número de fallecidos).

Fuente: elaboración propia. Ver anexo virtual.

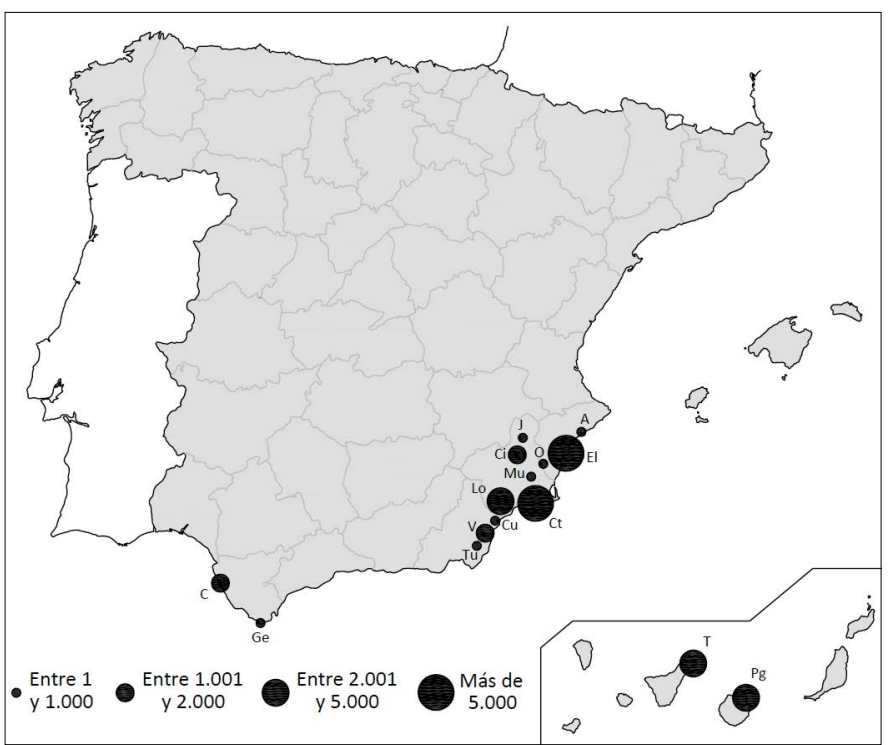

Figura 3. Localidades afectadas por la fiebre amarilla durante la oleada de 1810-1812 y magnitud de los brotes (número de fallecidos).

Fuente: elaboración propia. Ver anexo virtual.
Desde 1813 la frecuencia e intensidad de las epidemias en los puertos españoles se redujo. Durante los diez años siguientes destacó el brote de Cádiz en 1819, en el que fallecieron 5000 personas aproximadamente, y la cuarta oleada epidémica, de menor magnitud que las anteriores, en Cataluña y Baleares (ver figura 4). En esta ocasión, la mayor mortalidad se produjo en Barcelona con unos 18000 fallecidos, seguida de Palma con más de 5000 (B y P en la figura 4). Desde entonces, la población de la España peninsular quedó liberada de la enfermedad por medio siglo, hasta que en 1870 apareció de nuevo en poblaciones de Barcelona, Alicante y Valencia (véase anexo virtual). La distribución geográfica de las distintas oleadas evidencia que la intensificación del tráfico a lo largo del litoral mediterráneo no solo extendió la amenaza de contagio a los principales puertos comerciales, sino también a sus zonas de influencia.

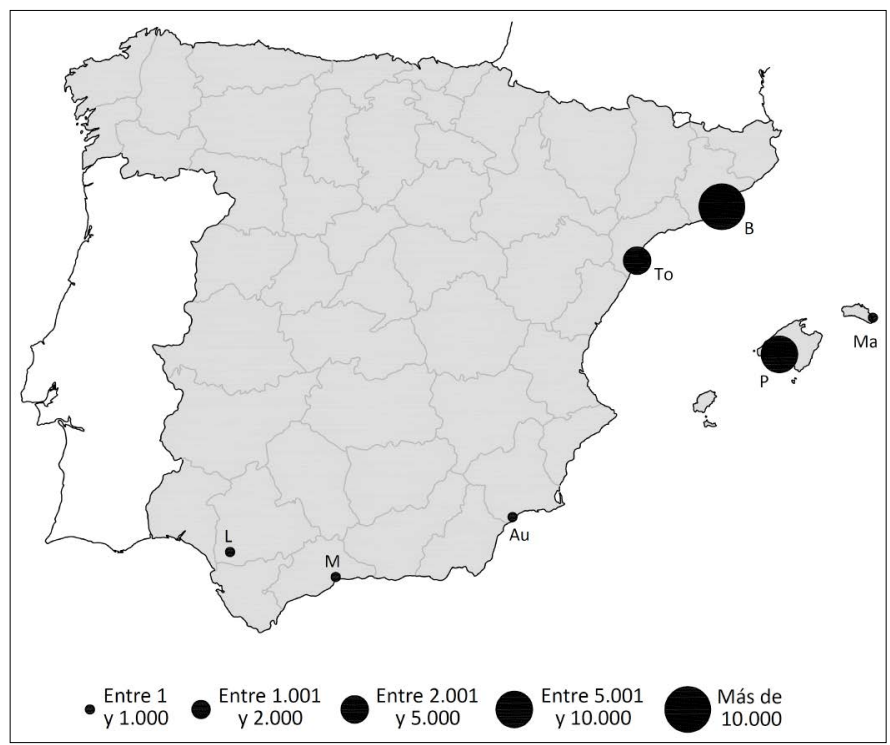

Figura 4. Localidades afectadas por la fiebre amarilla durante la oleada de 1821 y magnitud de los brotes (número de fallecidos).

Fuente: elaboración propia. Ver anexo virtual.

La frecuencia y extensión de los brotes de fiebre amarilla en las costas peninsulares muestra relación con el comercio colonial. Dos de los periodos de mayor incidencia (1804 y 1810-1812) coinciden con la recuperación mercantil de España con las colonias, como consecuencia de la Paz de Amiens y con la reactivación del tráfico comercial, que se había vuelto a interrumpir entre finales de 1804 y 1808 por el nuevo bloqueo marítimo y la derrota de Trafalgar en 1805 (Pérez Serrano, 1992, pp. 35-37; Fisher, 1993; Cuenca-Esteban, 2008). A partir de 1808, a pesar de la Guerra de la Independencia (1808-1814), el comercio se pudo recuperar gracias a la nueva alianza con los ingleses, lo que, como señala García-Baquero (1984, p. 133), permitía a Cádiz tener expedita la puerta del mar y la vuelta a una relativa normalidad.

La pérdida del imperio continental americano entre la ocupación francesa y el Trienio Liberal clausuró unos mercados privilegiados para el comercio y redujo las exportaciones e importaciones españolas con estos territorios (García-Baquero, 1984; Fisher, 1993; Prados de la Escosura, 1993; Cuenca-Esteban, 2008). Una de las consecuencias fue la reducción del riesgo de contagio de fiebre amarilla.

El comercio con América era una condición necesaria para el contagio de fiebre amarilla, pero no suficiente. Eran necesa- 
rios otros factores geoepidemiológicos, entre los que destacan la presencia del agente causal en los puertos de exportación americanos, así como la existencia de mosquitos que permitiesen el contagio entre individuos en el destino (Baldwin, 1999, pp. 211-226). La presencia del vector estaba asegurada en el Mediterráneo español, puesto que se trata de lugares donde el clima permitía a los mosquitos que la transmiten -los Aedes aegypti- desempeñar sus funciones de transmisores de la enfermedad (Nadal, 1966, pp. 100-108; Toledo Curbelo, 2000). Este factor explica la mayor incidencia que tuvo la fiebre amarilla en las costas españolas en contraposición a la que tuvo en otras latitudes ${ }^{6}$.

En este sentido, pese a que hay constancia de epidemias en algunas ciudades mexicanas desde mediados del xvi (Vainio y Cutts, 1998, p. 16; Tomori, 2002, p. 195; Gragg, 2003; Barrett y Higgs, 2007, pp. 210, 219; McNeill, 2010), los periodos de mayor intensidad de episodios epidémicos en los lugares de las Américas que concentraban el grueso del comercio colonial también guardan relación con los registrados en España. Por ejemplo, en la ciudad de Veracruz - principal puerto comercial de Nueva España- la fiebre amarilla cobró particular importancia a partir de 1794 (Bustamante, 1958; Torres Muñoz, 1966; González Maroño, 2004). La enfermedad apareció tras un periodo de veintiséis años ausente. A partir de este momento y durante todo el siglo xIx los brotes epidémicos fueron frecuentes, destacando por el número de fallecidos el de 1812 (González Maroño, 2004; Méndez Maín, 2010, p. 14). La ciudad estaba ubicada en una zona húmeda y pantanosa, donde proliferaban los mosquitos. Además, el intenso movimiento de personas que caracterizaban al puerto de Veracruz favorecía la constante presencia de individuos sin inmunidad adquirida y, por tanto, susceptibles de contraer y transmitir la enfermedad (González Maroño, 2004, pp. 53-54). En La Habana, el mayor ciclo epidémico se produjo durante la guerra de los Diez Años (1868-1878), coincidiendo con los últimos brotes registrados en las costas españolas -Barcelona, Alicante y Valencia en 1870, además del que se produjo en Madrid en 1878-. En los diez años de guerra murieron más de 20000 militares españoles por fiebre amarilla (Martínez Fortun-Foyo, 1952; Toledo Curbelo, 2000).

Desde la perspectiva de la inmunidad, la apertura al comercio colonial de nuevos puertos peninsulares puso en riesgo de contagio a una gran masa de población que jamás había tenido contacto con la misma. En esta época, previa al descubrimiento de la vacuna ${ }^{7}$, la práctica totalidad de la población de estos territorios era susceptible de contraer la enfermedad. Esta circunstancia podría explicar los elevados niveles de mortalidad de algunas localidades durante los brotes de 1800 y $1803-$ 1804, en contraposición a los más bajos constatados en brotes posteriores (ver anexo virtual).

\footnotetext{
${ }^{6}$ En relación con brotes en el territorio del Reino Unido existen registros de un brote epidémico en 1826 en Dublín del que se desconoce la magnitud (Vainio y Cutts, 1998, p. 64), de un pequeño episodio en Southampton en 1852 (Vainio y Cutts, 1998, p. 64) y del acaecido en el puerto de Swansea en 1865, en el que fallecieron 15 personas (Meers, 1986). Para el caso francés existen evidencias de la aparición de la enfermedad en el puerto de Saint Nazaire en 1843 y 1861 (Guijarro Oliveras, 1948; Coleman, 1984). En la mayoría de estos casos el brote epidémico se produjo durante meses especialmente cálidos, el número personas fallecidas fue reducido y los contagios se concentraron en zonas portuarias (Meers, 1986; Coleman, 1987).

${ }^{7}$ No fue hasta principios de la década de 1930 cuando se utilizó el virus atenuado de Theiler para inocularlo con éxito en personas (Gardner y Ryman, 2010, pp. 237-238; Monath, 2010, pp. 161-176)
}

Las evidencias disponibles para Jerez muestran cómo, tras el fuerte impacto que tuvo el brote de 1800 , la mortalidad asociada al de 1804 es mínima. Algo similar sucede en Sevilla, al quedar liberada de la fiebre amarilla durante casi dos décadas tras el fallecimiento de un 182 por mil de su población en el brote de 1800; o en Málaga, donde tras la muerte de 18348 personas entre 1803 y 1804 no hay constancia de la reaparición de la enfermedad hasta 1821 . En el caso de Alicante es probable que la inmunidad adquirida tras el brote de 1804 explique el reducido número de fallecidos de la epidemia de 1811. Las evidencias presentadas por Sawchuk y Burke (1998) en los sucesivos brotes de fiebre amarilla que afectaron a Gibraltar en 1804, 1810, 1813, 1814 y 1828 apuntan también a la influencia de este mecanismo.

Los brotes de fiebre amarilla que se dieron en Cádiz a lo largo del siglo xviII no generaron, aparentemente, ese efecto de inmunidad de grupo que hubiera atenuado el impacto del contagio a lo largo del tiempo. Por el contrario, la epidemia de 1800 resultó particularmente letal y diezmó al 19\% de la población, con casi 11000 fallecidos. Dos factores debieron influir en este recrudecimiento de la virulencia: en primer lugar, el tiempo transcurrido desde el anterior brote, que había ocurrido veinte años antes, por lo que apenas habría recuerdo de la población inmunizada; $y$ en segundo lugar, el enorme porcentaje de población foránea que constituía la población gaditana derivada de los intensos flujos migratorios (Pérez Serrano, 1992; Molina Martínez, 2004). La magnitud de este episodio sí pudo tener un efecto inmunizador a la vista de la reducción en los fallecimientos en los sucesivos episodios de 1804, 1810 y 1813. Este efecto beneficioso debió haberse debilitado a la altura de 1819, a la vista del nuevo incremento en el número de difuntos que, no obstante, fue la mitad del de 1800 .

El efecto reductor que tenía sobre los niveles de mortalidad la presencia de población inmune era doble: directo -puesto que la población que ha padecido la enfermedad no puede volver a contagiarse- e indirecto -ya que tampoco pueden actuar como reservorio del virus en futuros brotes, reduciendo así la capacidad de reproducción de la enfermedad- (Pritchett y Tunali, 1995; Sawchuk y Burke, 1998; Massad et al., 2003; Clark, 2008; McNeill, 2010, pp. 44-52).

\section{Debate científico y respuesta institucional}

El ciclo epidémico de fiebre amarilla de las primeras décadas del siglo xIX atrajo un enorme interés científico en su época. Las monografías médicas fueron numerosas en esos años: Cibat, 1804; Devèze, 1804; Aréjula, 1806; Mellado, 1811; Serrano, 1812; Cabanellas, 1814; Fellowes, 1815; Maclean, 1817; Romero y Velázquez, 1819; Bahí, 1822; Salamanca, 1822. Las discusiones girarán en torno al origen de la enfermedad, a las condiciones de propagación, así como a las medidas curativas o paliativas que pudiesen adoptarse. Estas publicaciones tuvieron un efecto en la reforma de la Administración sanitaria y en la introducción de algunas medidas inspiradas en el higienismo. Destaca su influencia en el Proyecto de Código Sanitario de 30 de abril de 1822 y en la Ley Orgánica de Sanidad de 1855 (Rodríguez Ocaña, 1987; Santonja, 1998; Feria Lorenzo, 2012, 2016; Hamer-Flores, 2018).

Un aspecto destacable de la fiebre amarilla es la escasa relación existente entre el estado nutricional de los individuos y las posibilidades de superar la enfermedad una vez contraída. Su virulencia provoca que el factor determinante sobre las posibilidades de fallecimiento no sea la resistencia a la misma, 
sino el grado de exposición (VV. AA, 1983). La fiebre amarilla no se contagia directamente entre personas. Para contraer la enfermedad es necesario que a la persona le pique un mosquito infectado. Por esta razón, en lugares con alta densidad de población y con intensa actividad de mosquitos, las posibilidades de contagio aumentan significativamente (Monath, 2001; Gardner y Ryman, 2010, pp. 242-243). Además, durante la enfermedad los individuos contagiados desarrollan anticuerpos que son capaces de eliminar el virus y proporcionar una inmunidad duradera (Restrepo, 2004, p. 74).

En las primeras décadas del xix, la causa de esta enfermedad y sus mecanismos de propagación solían atribuirse a influencias atmosféricas, miasmáticas y meteorológicas, pero en ningún caso a la picadura del mosquito (Barona Vilar, 1993; Urquía, 2006). Con todo, algunas de las recomendaciones propuestas por la teoría médica dominante se centraban en aspectos que influían en el desarrollo de la misma, lo que condujo a intervenciones preventivas efectivas (Duffy, 1971; Coleman, 1987; Preston y Haines, 1991, p. 8; Urquía, 2006, p. 23). Igualmente, en la literatura especializada de la primera mitad del siglo xIx se señalaban circunstancias que están relacionadas con la actividad del mosquito y que son elementos necesarios para el desarrollo de la enfermedad. Por ejemplo, la identificación de las altas temperaturas como condición para la proliferación de la fiebre amarilla se repite en la práctica totalidad de trabajos de la época (Cibat, 1804, p. 49; Devèze, 1804; Dubois, 1844, p. 351; Buenrostro, 1858, pp. 66-67).

Respecto al ámbito geográfico, el hecho de que la enfermedad se producía por contacto con personas u objetos procedentes de parajes infectados y de que fuera endémica en América estaba relativamente extendido en las distintas monografías de la época (Cibat, 1804, p. iv). Además, se identificaba a las desembocaduras de los ríos como los espacios en los que con más frecuencia se desarrollaba (Buenrostro, 1858, pp. 66-67).

Otro aspecto que se repite en los trabajos contemporáneos está relacionado con la inmunidad adquirida tras el contagio, así como la menor incidencia de la enfermedad en las personas nativas de las zonas en que era endémica (Devèze, 1804; Dubois, 1844, p. 352; Buenrostro, 1858). Aréjula afirmó que

el que ha tenido una vez la epidemia no la vuelve a sufrir; (esto) es más constante aún que el que no la tiene no la puede pegar [...] por todo esto he puesto un gran cuidado en no enviar ni dexar venir a pueblo epidemiado ningún médico que no hubiese pasado la epidemia o estado lago tiempo en nuestras Américas septentrionales; pues de hacerlo, corrían grande riesgo de padecerla, y aumentarían el número de enfermos los mismos que venían al socorro de estos (Aréjula, 1806, pp. 314-315).

En relación con las medidas de prevención, es importante tener presente que durante la primera mitad del siglo xix el debate médico sobre la enfermedad oscilaba en torno a si el contagio se producía por el contacto con personas enfermas o si, por el contrario, bastaba con hallarse en una zona infestada (Aréjula, 1806; Dubois, 1844; Buenrostro, 1858). En este debate existía un trasfondo económico derivado del perjuicio económico que ocasionaban las medidas sanitarias a las que hemos hecho referencia (Beltrán Moya, 2006, pp. 133-140; DeLacy, 2017, pp. 188-195).

Uno de los efectos de las epidemias de fiebre amarilla es que la mortalidad no se distribuye homogéneamente en el territorio. Solía afectar con mayor intensidad a determinados barrios de las urbes y pasar casi desapercibida en las zonas rurales e incluso en el hinterland de las propias ciudades (Pritchett y Tunali, 1995; Luque de Haro, 2020, pp. 216-266). Estas diferencias fueron ya evidentes para muchos contemporáneos y, consecuentemente, recomendaron la salida de la población sana al campo como medio de evitar el contagio (Aréjula, 1806, p. 375; Arruti, 1824, p. 143).

En lo que concierne al tratamiento, las medidas contempladas en la literatura de la época debieron ser mucho menos eficaces -cuando no contraproducentes- que las destinadas a evitar la exposición. Son frecuentes las alusiones a la conveniencia de las sangrías, de aplicar friegas corporales o administrar bebidas diluentes o actuar en la detención de los vómitos (Dubois, 1844, p. 358). También se propone el uso del sulfato de quinina (Buenrostro, 1858, p. iv), al que la mayoría de los autores reconocen ventajas frente a la quina (Arruti, 1824, p. 144).

¿Cómo respondieron los poderes públicos de la época a este ciclo epidémico? En España, durante el siglo xviI y hasta la llegada del liberalismo, el sistema sanitario se restringía básicamente a la protección de la salud de la población frente a enfermedades catastróficas o epidémicas. La Administración de la salud pública descansaba, de forma predominante, en los ayuntamientos. Otro elemento característico de este modelo de organización sanitaria era la combinación de funciones consultivas y ejecutivas, tanto a nivel municipal como del Gobierno central (Rodríguez Ocaña, 1987; Rodríguez Ocaña y Martínez Navarro, 2008).

La emergencia sanitaria provocada por la fiebre amarilla determinó la ampliación del sistema de juntas de sanidad. Mediante la Real Orden del 30 de septiembre de 1800, se instauraron en todas las capitales de provincia y en las localidades cabeza de partido judicial, añadiéndose a las ya existentes, desde al menos 1720 , en los principales puertos marítimos (Rodríguez Ocaña, 1987). El sistema contaba entre sus organismos con la Junta Suprema de Sanidad, encargada de recoger información sobre el estado de la salud de los territorios con los que España tenía relaciones comerciales a fin de establecer las debidas precauciones (Rodríguez Ocaña y Martínez Navarro, 2008, pp. 2226). El ciclo de fiebre amarilla motivó que las primeras décadas del siglo xIx coincidieran con los años de mayor actividad de la Junta Suprema (Rodríguez Ocaña, 1987). A partir de noviembre de 1813 se produjo una racionalización del sistema de juntas de sanidad, regulando una graduación de las jurisdicciones ante los numerosos conflictos que se suscitaban entre los diferentes organismos (Carrillo y García Ballester, 1980; Rodríguez Ocaña, 1987; Rodríguez Ocaña y Martínez Navarro, 2008, p. 44).

La principal estrategia de lucha contra las epidemias, una vez declaradas, eran los cordones sanitarios y las cuarentenas. Las características geoepidemiológicas del litoral español, unidas a la limitada capacidad estatal en materia sanitaria, son dos factores que explican la tradición cuarentenaria de España, compartida con otros países europeos como Grecia o Italia (Baldwin, 1999, pp. 211-226 y 236-243). Tanto los cordones como las cuarentenas se basaban en los preceptos contagionistas y tenían el objetivo de evitar el contacto de los enfermos con la población sana (DeLacy, 2017, pp. 95, 260). Por su propia naturaleza, este tipo de medidas dificultaban los flujos comerciales en el corto plazo (Pascual Artiaga, 1999; Betancor Gómez, 2000; Artiaga, 2002). Así, la parálisis del comercio y la hibernación de la economía provocaban la caída de la producción, el endeudamiento de agricultores y artesanos y la quiebra de compañías comerciales e industriales (Delgado Ribas, 1987). Los datos recopilados por Gámez Amián (1994, pp. 95-96) dan cuenta de la repercusión en este sentido del brote epidémico de 1804 en Málaga. Sin 
embargo, cuando estas medidas preventivas tenían éxito, favorecían una rápida recuperación económica al evitar la pérdida de capital humano y el deterioro de la confianza de los socios comerciales, favoreciendo su aceptación por amplias capas de los comerciantes al considerarlos un mal menor (Salas-Vives, 2010, p. 80-83; Salas-Vives y Pujadas-Mora, 2018).

Aunque las juntas locales trataban de asegurar el abastecimiento de alimentos para la población, las restricciones al comercio provocaban situaciones dramáticas de escasez de subsistencias. Estas medidas de restricción de la movilidad no se levantaban hasta considerar extinto el brote epidémico. Además, para evitar rebrotes, se fumigaron la mayor parte de las localidades afectadas (Guiton de Morveau, 1805; Aréjula, 1806; Cabanellas, 1814) ${ }^{8}$.

\section{Aprendizaje social y desigualdad}

En el contexto de una crisis epidémica el conflicto entre los intereses privados y el interés social se agudiza. Las conductas de las personas, el comportamiento de las clases sociales e incluso de la organización administrativa se veían expuestas a condiciones extremas de lucha por la propia supervivencia (Pérez Moreda, 1980, p. 86; Serrallonga i Urquidi, 1996). Eran momentos en los que las circunstancias y el miedo impulsaban reacciones de desesperación individual y pánico colectivo, así como actuaciones negligentes de autoridades e instituciones que solían ser reacias a reconocer el mal que afligía a la población para retrasar o evitar los perjuicios económicos derivados (Hamer-Flores, 2018; Pérez Moreda, 2020).

Las actuaciones de las juntas de sanidad no siempre coincidían con el interés individual. Los cordones sanitarios constreñían la libertad de movimiento y suponían un grave perjuicio para comerciantes, productores y consumidores. Las cuarentenas aumentaban el riesgo de contagio de aquellos que, bajo sospecha de estar enfermos, tenían que compartir espacio con otros infectados. Las labores de limpieza y guarda de calles o puertas de la ciudad implicaban una obligación y un riesgo que, frecuentemente, no estaba siquiera remunerado. Por ello, las autoridades imponían castigos para quienes contraviniesen sus órdenes. Sin embargo, las personas de mayor estatus socioeconómico solían acogerse a mecanismos que les permitían eludirlas o sustituirlas por otras prácticas menos arriesgadas (Luque de Haro, 2020, pp. 239, 387).

Las recomendaciones de los expertos de abandonar las poblaciones infectadas y el recuerdo de sucesos epidémicos anteriores constituían un incentivo para abandonar las ciudades cuando la amenaza de contagio era evidente. Así lo muestran los datos relativos a la población que se ausentó de Málaga durante el brote de 1804 en relación con la que lo hizo en el de 1803 (ver figura 5). El aumento en el número de ausentes sugiere una especie de aprendizaje social. Mientras que antes de 1803 no tenemos evidencias de que la ciudad hubiese padecido un suceso epidémico similar, en 1804 el recuerdo del año anterior estaba muy próximo. Esto, unido a las indicaciones de los especialistas, influiría en la percepción del riesgo de permanecer en la ciudad. Ante las noticias de la reaparición de la enfermedad, aquellos con posibilidades habrían tratado de evitar la exposición huyendo.

\footnotetext{
${ }^{8}$ Para más información sobre la composición de las juntas de sanidad local, de sus funciones y capacidades, ver Rodríguez Ocaña (1987); Rodríguez Ocaña y Martínez Navarro (2008).
}

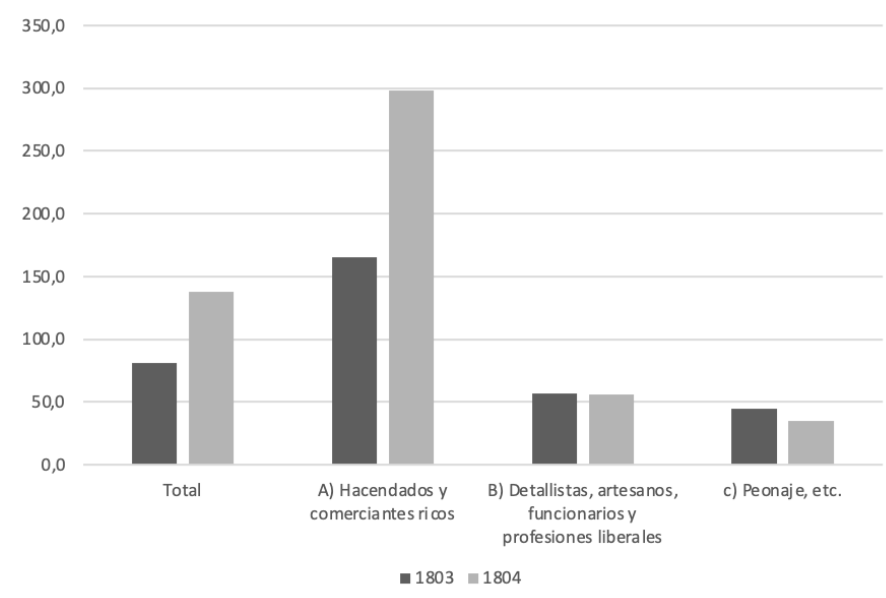

Nota: \% de ausentes sobre el total de la población de Málaga al inicio de cada brote.

Figura 5. Tasa de huida en Málaga durante los brotes de 1803 y 1804.

Fuente: Aréjula (1806, p. 475-476) y Carrillo y García Ballester (1972, pp. 83-84).

Sin embargo, no todo el mundo tenía la misma capacidad para huir. Según Link y Phelan $(1995,1996,2002)$ en su hipótesis de las Social conditions as fundamental causes of disease, el control diferencial que tienen los individuos de distintas clases sociales sobre recursos como el dinero, el conocimiento, el prestigio, el poder y las conexiones sociales ocasiona un menor riesgo de fallecimiento entre los de mayor estatus socioeconómico. Estos recursos eran determinantes para esquivar el contagio, lo que se refleja en las diferencias entre clases sociales en relación con el fenómeno de la "huida» (Serrallonga i Urquidi, 1996). Quienes contaban con más recursos para hospedarse en alguna propiedad exterior, disponían de un mejor acceso a la información o podían tener un trato diferencial de las autoridades tenían mayor capacidad de reducir la exposición. De esta manera, aquellos individuos con mayor acceso a determinados recursos (educacionales, monetarios, relacionales, etc.) habrían sido los primeros en beneficiarse del avance en el conocimiento (Clouston et al., 2016, p. 1636).

Si bien las evidencias cuantitativas sobre el fenómeno de la huida se reducen a las presentadas, existe un mayor número de evidencias cualitativas de la mayor propensión de las clases acomodadas a abandonar las zonas infectadas por fiebre amarilla. Así se constata en La Carlota durante la epidemia de 1800 (Hamer-Flores, 2018), en Alicante durante el episodio de 1804 (Pascual Artiaga, 1999), en Vera durante el brote de 1811 (Luque de Haro, 2020, pp. 216-265), en Lorca en el año 1812 (Mula Gómez, 1980) y en Las Palmas durante la epidemia de 1838 (Betancor Gómez, 2000). La huida de las personas más pudientes tenía como consecuencia una dejación de sus funciones institucionales (Mula Gómez, 1980; Pérez Moreda, 1980, pp. 218-231). Los que permanecían en la ciudad no solo estaban expuestos a la epidemia, sino que además quedaban en una situación de ausencia institucional, a nivel asistencial, sanitario y de orden, que agravaba aún más la situación (Serrallonga i Urquidi, 1996; Luque de Haro, 2020).

En cuanto al riesgo de fallecimiento por fiebre amarilla, debido a la escasa relación existente entre el estado nutricional y las posibilidades de superar la enfermedad una vez contraída, el factor determinante sobre las posibilidades de 
fallecimiento no era la resistencia a la enfermedad, sino el grado de exposición (VV. AA, 1983). Además, la escasa eficacia de los tratamientos médicos de la época es improbable que derivase en una ventaja para aquellos que tenían un mayor acceso a los mismos. Por lo tanto, aunque la tasa de letalidad debió ser similar entre los distintos segmentos sociales, la capacidad de reducir la exposición en función del estatus socioeconómico habría conllevado una mayor mortalidad entre quienes tenían menores posibilidades de abandonar las zonas infectadas.

Un estudio reciente que analiza las diferencias sociales en la mortalidad en Vera (Almería) entre 1800-1812 parece confirmar esta hipótesis (Luque de Haro, Pujadas-Mora y García-Gómez, 2021). Esta ciudad sufrió el impacto de la fiebre amarilla en 1804, 1811 y 1812. Mientras que antes de 1804 no tenemos evidencias de que la ciudad hubiese padecido un suceso epidémico de importancia, en los dos brotes siguientes el recuerdo estaba muy próximo. En esta ocasión los médicos alertaron del riesgo que suponía pernoctar en la ciudad y, como atestiguan las actas de la Junta de Sanidad local ${ }^{9}$, fue habitual entre los más pudientes abandonar el núcleo urbano para alojarse en viviendas ubicadas en el extrarradio de la ciudad. Atendiendo a los resultados de supervivencia vemos cómo, mientras que en el periodo que incluye los meses en que se produjeron los fallecimientos derivados del brote de 1804 no hay diferencias entre clases sociales, durante los años en los que se produjeron las epidemias de 1811 y 1812 sí existió una clara desigualdad en los niveles de mortalidad de los distintos colectivos (ver figura 6).

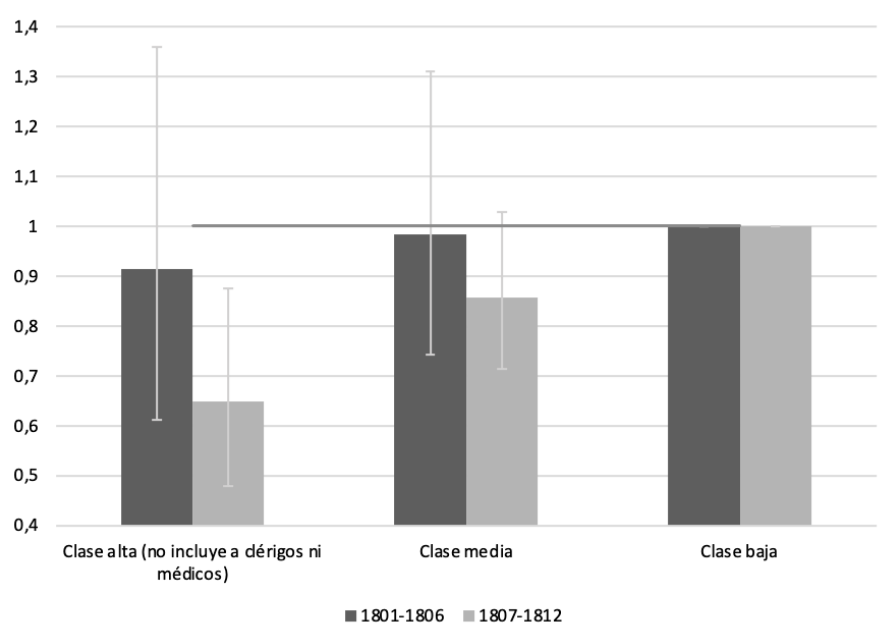

Nota: determinantes de la mortalidad infecciosa en Vera durante el periodo 1801-1806 y 1807-1812 a partir de análisis de supervivencia de riesgos competitivos. Resultados controlados por sexo, edad, barrio de residencia y número de individuos con los que cohabita. IC $=95 \%$. Clasificación de ocupaciones a partir del esquema HISCO (Van Leeuwen, Maas y Miles, 2002) y HISCLASS (Van Leeuwen y Maas, 2011). La exclusión de los clérigos y médicos de la clase alta y su inclusión en la clase media se justifica por la mayor exposición asociada a sus labores. Para más información ver referencia bibliográfica.

Figura 6. Diferencias sociales en la mortalidad infecciosa estimadas para la ciudad de Vera entre 1801-1806 y 1807-1812.

Fuente: Luque de Haro, Pujadas-Mora y García-Gómez (2021).

\footnotetext{
${ }^{9}$ Ver los puntos 6, 7 y 8 de las Actas de la Junta de Sanidad de Vera del 2 de octubre 1811, legajo 671, Archivo Municipal de Vera.
}

\section{Conclusiones}

La aparición de la fiebre amarilla en las costas peninsulares fue una consecuencia de la integración de los principales puertos en el sistema comercial atlántico y de las transformaciones ecológicas y demográficas que se produjeron en los puertos coloniales que concentraban el comercio con la metrópolis. Conforme la relación comercial se debilite, tras la emancipación americana, los brotes epidémicos también remitirán (Carrillo y García Ballester, 1980).

Es destacable el impacto científico y normativo de las epidemias de fiebre amarilla de comienzos del siglo xIx. Los problemas sanitarios derivados de esta epidemia ocasionaron un proceso de racionalización y ampliación del sistema sanitario. El resultado de la enfermedad fue, como lo es hoy la pandemia del coronavirus, muy diverso desde el punto de vista territorial, y la respuesta más común se articuló a través de una medida equivalente a lo que ahora denominamos confinamiento o distanciamiento social, y que a comienzos del Ochocientos respondía a la larga tradición de las cuarentenas. Entonces no se implementó en un amplio territorio bajo la autoridad del Gobierno del Estado y con intención preventiva, como en la actualidad, sino que en las postrimerías del Antiguo Régimen se resolvía en iniciativas dispersas, protagonizadas por autoridades locales desbordadas ante la epidemia, escasamente coordinadas y con un alcance territorial limitado. El estudio de la fiebre amarilla de comienzos del xix permite de este modo fijarnos en la importancia del marco institucional, más allá de las características epidemiológicas de la enfermedad, en el análisis de una coyuntura de mortalidad catastrófica (Gutierrez Aroca, Fernández-Pacheco y Gutiérrez Parera, 2017).

Los datos relativos a la incidencia de las epidemias, medidas por el número de fallecidos, permiten sugerir la importancia del efecto de la inmunidad para disminuir la intensidad en la repetición de los brotes. Esa idea ya había sido señalada por McNeill para el caso de Centroamérica y el Caribe y habría tenido una repercusión favorable para el mantenimiento de las posesiones españolas en aquella área. En el balance entre el porcentaje de la población inmunizada, fruto de un ataque inmediatamente anterior, y la presencia de foráneos en poblaciones con elevados saldos migratorios positivos, se podrán encontrar claves para investigaciones futuras sobre este aspecto.

También hemos detectado que la desigualdad social ante el contagio y el riesgo de fallecimiento tiene que ver con la puesta en práctica de procesos de aprendizaje social acumulado ante la experiencia de anteriores brotes y la posibilidad, diferente según los grupos sociales, para emprender la huida y disminuir la exposición al contagio. Los datos disponibles para algunas poblaciones como Málaga, así como el análisis más robusto que se hizo para el brote de Vera en 1804 y 1811-1812, son bastante concluyentes al respecto.

\section{Bibliografía}

Alfani, G. (2020). Pandemics and asymmetric shocks: evidence from the history of plague in Europe and the Mediterranean. CAGE online Working Paper Series, 478.

Alfani, G. y Murphy, T. E. (2017). «Plague and Lethal Epidemics in the Pre-Industrial World", The Journal of Economic History, 77 (1), 314-343. Disponible en: $10.1017 /$ S0022050717000092.

Aréjula, J. M. de (1806). Breve descripción de la fiebre amarilla padecida en las andalucías. Madrid: Imprenta Real. 
Arruti, E. F. (1824). «Memoria sobre la naturaleza, carácter, contagio y tratamiento de la fiebre amarilla», Periódico de la Sociedad Médico-Quirúrgica de Cádiz, 135-145.

Artiaga, M. P. (2002). «La Ciudad Ante el Contagio: Medidas Políticas Y Administrativas Dictadas en la Epidemia de Fiebre Amarilla de 1804 en Alicante», Asclepio, 54 (1), 125-153.

Augustin, G. (1909). History of Yellow Fever. Nueva Orleans: Searcy and Peaff

Bahí, J. F. (1822). Relacion médico-politica sobre la aparicion de la fiebre amarilla a ultimos de julio y principios de agosto de 1821 en las tripulaciones de los buques del puerto de Barcelona, y sus progresos en la Barceloneta é introduccion en la ciudad. Barcelona: Imprensa de la Viuda Roca.

Baldwin, P. (1999). Contagion and the State in Europe, 1830-1930. Cambridge: Cambridge University Press.

Barona Vilar, J. L. (1993). «Teorías médicas y la clasificación de las causas de muerte», Boletín de la ADEH, 11 (3), 49-64.

Barrett, A. D. T. y Higgs, S. (2007). "Yellow Fever: A Disease that Has Yet to be Conquered", Annual Review of Entomology, 52 (1), 209-229. Disponible en: 10.1146/annurev.ento.52.110405.091454.

Barrett, A. D. T. y Monath, T. P. (2003). «Epidemiology and ecology of yellow fever virus", Advances in Virus Research, 61, 291-317.

Beltrán Moya, J. L. (2006). Historia de las epidemias: en España y sus colonias (1348-1919). Madrid: La Esfera de los Libros.

Benedictow, O. J. (2018). The Black Death 1346-1353: The Complete History. Woodbridge: Boydell Press.

Bennett, J. E., Dolin, R. y Blaser, M. J. (2020). Principles and Practice of Infectious Diseases, The American Journal of Tropical Medicine and Hygiene. Disponible en: 10.4269/ajtmh.1986.35.3.tm0350030671b.

Betancor Gómez, M. J. (2000). «Epidemia y conflictividad social: la fiebre amarilla de 1838 en Las Palmas», en XIII Coloquio de Historia Canario-Americana; VIII Congreso Internacional de Historia de America (AEA)(1998). Cabildo de Gran Canaria, pp. 2501-2511.

Buenrostro, F. (1858). Biografía de la Fiebre Amarilla. La Habana: Imprenta del Tiempo.

Bustamante, M. (1958). La fiebre amarilla en México y su origen en América. México DF: Instituto de Salubridad y Enfermedades Tropicales.

Bustos Rodríguez, M. (2008). "Comercio y comerciantes en la Andalucía del Antiguo Régimen: Estado de la cuestión y perspectivas», Obradoiro de Historia Moderna, 17, 43-76.

Cabanellas, M. (1814). Reflexiones sobre varios puntos de la breve descripción de la fiebre amarilla de Andalucía, escrita por el doctor D. Juan Manuel de Arejula. Madrid: Repulles.

Carrillo, J. L. y García Ballester, L. (1972). «El comportamiento de las clases y grupos sociales de Málaga en las epidemias de fiebre amarilla», Cuadernos de Historia de la Medicina Española, 11, 77-116.

Carrillo, J. L. y García Ballester, L. (1980). Enfermedad y sociedad en la Málaga de los siglos XVIII y XIX. La fiebre amarilla (1741-1821). Málaga: Universidad de Málaga.

Chowell, G. et al. (2014). «Spatial-temporal excess mortality patterns of the 19181919 influenza pandemic in Spain», BMC Infectious Diseases, 14 (1), 1-12. Disponible en: 10.1186/1471-2334-14-371.

Cibat, A. (1804). Memoria sobre la calentura amarilla contagiosa. Barcelona: Imprenta de Brusí.

Cilek, L., Chowell, G. y Fariñas, D. R. (2018). «Age-specific excess mortality patterns during the 1918-1920 influenza pandemic in Madrid, Spain», American Journal of Epidemiology, 187 (12), 2511-2523. Disponible en: 10.1093/aje/ kwy 171.

Clark, G. (2008). A Farewell to Alms: a brief economic history of the world. Princeton: Princeton University Press. Disponible en: 10.1017/CB09781107415324.004.

Clouston, S. A. P. et al. (2016). «A Social History of Disease: Contextualizing the Rise and Fall of Social Inequalities in Cause-Specific Mortality", Demography, 53 (5), 1631-1656. Disponible en: 10.1007/s13524-016-0495-5.

Coleman, W. (1984). «Epidemiological Method in the 1860s: Yellow Fever at Saint-Nazaire», Bulletin of the History of Medicine, 58 (2), 145-163.

Coleman, W. (1987). Yellow Fever in the North: The Methods of Early Epidemiology. Wisconsin: University of Wisconsin Press.

Crosby, A. W. (1988). Imperialismo ecológico. La expansión biológica de Europa, 900-1900. Barcelona: Crítica.

Cuenca-Esteban, J. (2008). «Statistics of Spain's Colonial Trade, 1747-1820: New Estimates and Comparisons with Great Britain", Revista de Historia Económica; Journal of Iberian and Latin American Economic History, 26 (3), 323354. Disponible en: 10.1017/S0212610900000379.

Curtin, P. D. (1993). "Disease Exchange Across the Tropical Atlantic Author», History and Philosophy of the Life Sciences, 15 (3), 329-356.

De María, A. (1820). «Memoria sobre la epidemia de Andalucía el año de 1800 al 819». Cádiz: Imprenta de D. Antonio Murguia, p. 135.
DeLacy, M. (2017). «Contagionism Catches On. Medical Ideology in Britain, 1730 1800", Journal of Chemical Information and Modeling. Disponible en: 10.1017/ CB09781107415324.004.

Delgado Ribas, J. M. (1986). «Libre comercio: mito y realidad», en T. Martínez Vara (ed.), Mercado y desarrollo económico en la España contemporánea. Madrid: Siglo XXI, pp. 69-83.

Delgado Ribas, J. M. (1987). «El modelo catalán dentro del sistema de libre comercio», en Bernal Rodríguez, A. (ed.). El comercio libre entre España y América (1765-1824). Madrid: Fundación Banco Exterior, pp. 53-70.

Devèze, J. (1804). Dissertation sur la fièvre jaune qui régna à Philadelphie, en 1793 depuis le mois d'août jusque vers le milieu du mois de décembre. Paris: Huzard.

Dubois, C. F. (1844). «Fiebres tifoideas de América o fiebre amarilla, vomito negro fiebre de las Antillas», en Tratado de Patología general. Cádiz: Imprenta, Librería y Litografía de la Sociedad de la Revista Médica, pp. 350-359.

Duffy, J. (1971). "Social impact of disease in the late nineteenth century», Bulletin of the New York Academy of Medicine, 47 (7), 797-810.

Echeverri Dávila, B. (2018). «En el centenario de la gripe española: un estado de la cuestión ", Revista de Demografia Histórica, 36 (1), 17-42.

Eiros Bouza, J. M., Bachiller Luque, M. R. y Pérez Rubio, A. (2018). La gripe de 1918 : Centenario de una crisis sanitaria devastadora. Barcelona: Ediciones El Portal S.L.

Fellowes, J. (1815). Reports of the Pestilential Disorders of Andalusia, Which Appeared at Cadiz in the Years 1800, 1804, 1810, and 1813. London: Longman, Hurst Rees, Orme, and Brown, Paternoster-Row.

Feria Lorenzo, D. J. (2012). «La primera regulación sanitaria española : la ley orgánica de 1855», Revista de Historia das ideias, 33, 217-239. Disponible en: https://doi.org/10.14195/2183-8925_33_10.

Feria Lorenzo, D. J. (2016). La sanidad en el liberalismo isabelino. La promulgación de la ley de sanidad de 1855: debate parlamentario y análisis. Huelva: Servicio de Publicaciones Universidad de Huelva.

Fisher, J. R. (1981). «Imperial "Free Trade” and the Hispanic Economy,1778-1796», Journal of Latin American Studies, 13 (1), 21-56.

Fisher, J. R. (1993). El comercio entre España e Hispanoamérica (1797-1820), estudios de historia económica. Madrid: Imprenta del Banco de España.

Gámez Amián, A. (1994). Málaga y el comercio colonial con América (1765-1820). Málaga: Miramar.

García-Baquero, A. (1984). «Independencia colonial americana y pérdida de la primacía andaluza», en Historia de Andalucía. Barcelona: Planeta, pp. 117-149.

Gardner, C. L. y Ryman, K. D. (2010). "Yellow Fever: A Reemerging Threat», Clinics in Laboratory Medicine, 30 (1), 237-260. Disponible en: 10.1016/j. cll.2010.01.001.

González de Sámano, M. (1858). Monografía histórica del cólera morbo asiático. Madrid: Imprenta Manuel Álvarez.

González García, A. (2013). «Avances y tendencias actuales en el estudio de la pandemia de gripe de 1918-1919», Vínculos de Historia, 2, 309-330.

González Maroño, M. L. (2004). «Salud pública en el puerto de Veracruz a principios del siglo XIX», Ulúa, 2 (3), 27-63.

Gragg, L. (2003). «Englishmen Transplanted»: The English Colonization of Barbados 1627-1660. Oxford: Oxford University Press.

Guijarro Oliveras, J. (1948). "Aportación al estudio histórico de la fiebre amarilla», Anuario de Estudios Americanos, 5, 363-396.

Guiton de Morveau, L. B. (1805). Memoria sobre las disposiciones tomadas por e Gobierno para introducir en España el Método de fumigar y purificar la atmósfera. Madrid.

Gutierrez Aroca, J. B., Fernández-Pacheco, E. P. y Gutiérrez Parera, J. (2017). «La fiebre amarilla en Andalucía a comienzos del siglo xIX", Arte, Arqueología e Historia, (23-24), 191-203.

Hamer-Flores, A. (2018). «La epidemia de fiebre amarilla de 1800 y su impacto en La Carlota, capital de las Nuevas Poblaciones de Andalucía», Trocadero, 30 211-230.

Iglesias Rodríguez, J. J. (1987). La epidemia gaditana de fiebre amarilla de 1800. Jerez de la Frontera: Diputación provincial de Cádiz.

Jentes, E. S. et al. (2011). «The revised global yellow fever risk map and recommendations for vaccination, 2010: Consensus of the Informal WHO Working Group on Geographic Risk for Yellow Fever», The Lancet Infectious Diseases 11 (8), 622-632. Disponible en: 10.1016/S1473-3099(11)70147-5.

Kraemer, M. U. et al. (2015). "The global distribution of the arbovirus vectors Aedes aegypti and Ae. albopictus», eLife, 4. Disponible en: 10.7554/eLife.08347.

Le Roy Ladurie, E. (1973). «Un concept: l'unification microbienne du monde (XIVe-XVIIe siècles)», Le territoire de l'historien, 2, 37-97.

Link, B. G. y Phelan, J. C. (1995). "Social Conditions as Fundamental Causes of Disease», Journal of Health and Social Behavior, 35, 80-94. Disponible en: $10.2307 / 2626958$. 
Link, B. G. y Phelan, J. C. (1996). «Understanding sociodemographic differences in health. The role of fundamental social causes», American Journal of Public Health, 86 (4), 471-473. Disponible en: 10.2105/AJPH.86.4.471.

Link, B. G. y Phelan, J. C. (2002). «McKeown and the Idea That Social Conditions Are Fundamental Causes of Disease», American Journal of Public Health. American Public Health Association, 92 (5), 730-732. Disponible en: 10.2105/ AJPH.92.5.730.

Livi Bacci, M. (1990). Historia mínima de la población mundial. Barcelona: Ariel historia. Disponible en: 10.1017/СBO9781107415324.004.

Lobato Franco, I. y Oliva Melgar, J. M. (eds.). (2013). El sistema comercial español en la economía mundial (siglos XVII-XVIII). Homenaje a Jesús Aguado de los Reyes. Huelva: Universidad de Huelva.

Luque de Haro, V. (2020). Análisis histórico del nivel de vida en Andalucía. Desigualdad social y mortalidad: ensayo interpretativo y estudio empírico de un caso en el sureste español. Universidad de Almería.

Luque de Haro, V. A., Pujadas-Mora, J. M. y García-Gómez, J. J. (2021) «Inequality in Mortality in Pre-Industrial Southern Europe During an Epidemic Episode: Socio-Economic Determinants (Eighteenth - Nineteenth Centuries Spain)", Economics \& Human Biology, 40, pp. 1-17. doi: https://doi.org/10.1016/j. ehb.2020.100941.

Maclean, C. (1817). Results of an investigation respecting epidemic and pestilential diseases: including researches in the levant, concerning the plague. London: Thomas and George Underwood.

Martínez, A. L. L. (2010). «Cádiz y el comercio entre Europa y América a finales del siglo xviII. Una aproximación a partir de las pólizas de seguros marítimos», Jahrbuch für Geschichte Lateinamerikas. Anuario de Historia de America Latina, 47 (1), 213-246. Disponible en: https://doi.org/10.7767/jbla.2010.47.1.213.

Martínez Fortun-Foyo, J. A. (1952). «Epidemiología (síntesis cronológica)», Cuadernos de Historia Sanitaria, 5, 1-51.

Martínez Shaw, C. (1987). «Los comportamientos regionales ante el libre comercion, Manuscrits: revista d'historia moderna, 6, 75-89.

Martínez Shaw, C. y Oliva Melgar, J. M. (eds.). (2005). El sistema atlántico español, siglos XVII-XIX. Madrid: Marcial Pons Historia.

Massad, E. et al. (2003). «Dengue and the risk of urban yellow fever reintroduction in São Paulo State, Brazil», Revista de Saude Publica, 37 (4), 477-484. Disponible en: 10.1590/S0034-89102003000400013.

McNeill, J. R. (2010). Mosquito empires: Ecology and war in the greater Caribbean, 1620-1914, Mosquito Empires: Ecology and War in the Greater Caribbean, 1620-1914. Disponible en: 10.1017/СBO9780511811623.

McNeill, J. R. y McNeill, W. H. (2004). Las redes humanas: Una historia global del mundo. Barcelona: Editorial Crítica.

Meers, P. D. (1986). "Yellow fever in Sansea, 1865», J Hyg (Lond), 97 (1), 185191. Disponible en: $10.1017 /$ s0022172400064469.

Mellado, B. (1811). Historia de la epidemia padecida en Cádiz el año de 1810, y providencias tomadas para su extinción por las Juntas de Sanidad suprema del Reyno y su superior de esta ciudad. Cádiz: Imprenta Josef Niel.

Méndez Maín, S. (2010). «Las epidemias en Veracruz y su impacto en las políticas de salud y en la estructura de población 1821-1950», en Anales del IV Congreso ALAP 2010, Condiciones y Transformaciones Culturales Factores Económicos $y$ Tendencias Demográficas en Latinoamérica. La Habana, pp. 1-27.

Molina Martínez, J. M. (2004). De propios y extraños: la población de Cádiz en el siglo xVIII. Universidad de Cádiz.

Monath, T. P. (2001). «Yellow fever: an update», The Lancet Infectious Diseases, 1 (1), 11-20. Disponible en: 10.1016/S1473-3099(01)00016-0.

Mooney, G. (2015). Intrusive Interventions: Public Health, Domestic Space, and Infectious Disease Surveillance in England, 1840-1914. Woodbridge: NED, Boydell and Brewer.

Morillon, M., Mafart, B. y Matton, T. (2002). «Yellow fever in Europe during 19th century", en Bennike, P., Bodzsar, E. B., y Suzanne, C. (eds.). Ecological Aspects of Past Settlement in Europe. Budapest: Eötvös University Press, pp. 211-222.

Mula Gómez, A. J. (1980). «Mortalidad y comportamiento social en la Lorca de 1812", Anales de la Universidad de Murcia, 38 (4), 219-253.

Nadal, J. (1966). La población española: siglos XVI a XX. Barcelona: Ariel.

Pascual Artiaga, M. (1999). «Las reacciones de la población alicantina frente a la epidemia de fiebre amarilla de 1804», Revista de Historia Moderna, 17, 167192.

Pérez Moreda, V. (1980). Las crisis de mortalidad en la España interior. Siglos XVI-XIX, Madrid. Madrid: Siglo Veintiuno Editores.

Pérez Moreda, V. (2010). «Las crisis demográficas del periodo napoleónico en España», en La Parra López, E. (ed.), La guerra de Napoleón en España: reacciones, imágenes, consecuencias. Alicante: Publicaciones de la Universidad de Alicante, pp. 305-332.

Pérez Moreda, V. (2020). «Epidemias de la historia: lo que consiguió el miedo», La Razón, 14-4-2020. Disponible en: https://www.larazon.es/coronavirus/20200414/sf25ga3y4zgnvcs5cdkjlvmpci.html
Pérez Serrano, J. (1992). Cádiz, la ciudad desnuda. Cambio económico y modelo demográfico en la formación de la Andalucía contemporánea. Cádiz: Servicio de Publicaciones de la Ciudad de Cádiz.

Peset, J. L. (2011). «Las Guerras del Mosquito», Asclepio, 63 (2), 573-590. Disponible en: 10.3989/asclepio.2011.v63.i2.506.

Phillips, H. (2014). "The Recent Wave of 'Spanish' Flu Historiography», Social History of Medicine, 27 (4), 789-808. Disponible en: 10.1093/shm/hku066.

Prados de la Escosura, L. (1993). "La pérdida del Imperio y sus consecuencias económicas», en Prados de la Escosura, L. y Amaral, S. (eds.), La independencia americana: consecuencias económicas. Madrid: Alianza Universidad, pp. 253 329

Preston, S. y Haines, M. (1991). «The Social and Medical Context of Child Mortality in the Late Nineteenth Century", en Fatal Years: Child Mortality in Late Nineteenth-Century America Volume. Princeton: Princeton University Press, pp. 3-48.

Pritchett, J. B. y Tunali, I. (1995). «Strangers' Disease: Determinants of Yellow Fever Mortality during the New Orleans Epidemic of 1853", Explorations in Economic History, 32 (4), 517-539. Disponible en: 10.1006/EXEH.1995.1022.

Rawcliffe, C. y Clark, L. (eds.). (2013). «Looking for Yersinia Pestis: Scientists, Historians and the Black Death", en The Fifteenth Century XII: Society in an Age of Plague. Boydell and Brewer, pp. 15-38.

Restrepo, B. N. (2004). «Fiebre Amarilla», Revista CES Medicina, 18 (1), 69-82.

Ringrose, D. R. (1996). España, 1700-1900: el mito del fracaso. Madrid: Alianza Universidad.

Rodríguez Ocaña, E. (1987). «El resguardo de la salud. Organización sanitaria española en el siglo xvIII», Dynamis: Acta Hispanica ad Medicinae Scientiarumque Historiam Illustrandam, 7-8, 145-170.

Rodríguez Ocaña, E. y Martínez Navarro, F. (2008). «Salud pública en España: de la Edad Media al siglo xxI», en Nueva Salud Pública. Granada: Escuela Andaluza de Salud Pública, pp. 1-158.

Romero y Velázquez, R. (1819). Memoria que sobre el contagio de la fiebre amarilla extendió y presentó a la Real academia médico-práctica de Barcelona. Barcelona: Garriga y Aguasvivas.

Salamanca, J. M. (1822). Observaciones médicas, sobre el contagio de la fiebre amarilla y su introducción en esta ciudad en varias épocas desde el año de 1800 hasta el pasado de 21. Granada: Imprenta de Francisco de Benavides.

Santonja, J. L. (1998). «La construcción de cementerios extramuros: un aspecto de la lucha contra la mortalidad en el Antiguo Régimen», Revista de Historia Moderna, 17, 33-44.

Sawchuk, L. y Burke, S. (1998). «Gibraltar’s 1804 Yellow Fever Scourge: The Search for Scapegoats", Journal of the History of Medicine and Allied Sciences, 53, 3-42. Disponible en: 10.1093/jhmas/53.1.3.

Serrallonga i Urquidi, J. (1996). «Epidemias e historia social. Apuntes sobre el cólera en España, 1833-1865», Historia Social. Fundacion Instituto de Historia Social, 24, 7-21.

Serrano, D. (1812). Reflexiones médicas. Cartagena: Francisco Juan y Poveda.

Shaw-Taylor, L. (2020). «An introduction to the history of infectious diseases, epidemics and the early phases of the long-run decline in mortality $†$ ", Economic History Review, 73 (3), E1-E19. Disponible en: 10.1111/ehr.13019.

Snowden, F. (2019). Epidemics and Society. New Haven: Yale University Press.

Stein, S. y Stein, B. (2005). El apogeo del imperio: España y la nueva españa en la época de Carlos III, 1759-1789. Barcelona: Crítica.

Sykes, W. H. (1838). "Statistics of Cadiz.», Journal of the Statistical Society of London. [Royal Statistical Society, Wiley], 1 (6), 337-354. Disponible en: $10.2307 / 2337752$

Toledo Curbelo, G. J. (2000). «La otra historia de la fiebre amarilla en Cuba: 14921909», Revista Cubana de Higiene y Epidemiología, 38 (3), 220-227.

Tomori, O. (2002). «Fiebre amarilla en Africa: su impacto en salud pública y perspectivas para su control en el siglo xxI», Biomédica, 22 (2), 194-210. Disponible en: 10.7705/biomedica.v22i2.1157.

Torres Muñoz, A. (1966). «La fiebre amarilla en Méxieo. Erradieaeión del Aedes aegypti», Salud Pública de México, 8 (4), 561-570.

Urquía, M. L. (2006). Teorías dominantes y alternativas en epidemiología. II. Remedios de Escalada: EDUNLa Cooperativa.

Vainio, J. y Cutts, F. (1998). Yellow fever, World Health Organization. Ginebra.

Van Leeuwen, M. y Maas, I. (2011). Hisclass: A Historical International Social Class Scheme. Leuven: Universitaire Pers Leuven. Disponible en: 10.1080/01615440.2012.721340.

Van Leeuwen, M., Maas, I. y Miles, A. (2002). HISCO: Historical international standard classification of occupations. Leuven: Universitaire Pers Leuven.

Voigtländer, N. y Voth, H. J. (2013). «The three horsemen of riches: Plague, war, and urbanization in early modern Europe», Review of Economic Studies, 80 (2), 774-811. Disponible en: 10.1093/restud/rds034.

VV. AA (1983). «The Relationship of Nutrition, Disease, and Social Conditions: A Graphical Presentation», The Journal of Interdisciplinary History, 14 (2), 503506. Disponible en: $10.2307 / 203718$. 